\title{
Mesenteric abscess presents as left iliac fossa mass in postoperative case of inguinal hernia surgery with undescended testis
}

\author{
Monalisa Mahajan* \\ Department of Rotating House Physician, Bankura Sammilani Medical College and Hospital, Bankura, West Bengal, \\ India
}

Received: 10 June 2020

Revised: 04 July 2020

Accepted: 06 July 2020

*Correspondence:

Dr. Monalisa Mahajan,

E-mail: monalisamahajan96@gmail.com

Copyright: () the author(s), publisher and licensee Medip Academy. This is an open-access article distributed under the terms of the Creative Commons Attribution Non-Commercial License, which permits unrestricted non-commercial use, distribution, and reproduction in any medium, provided the original work is properly cited.

\begin{abstract}
An abscess is a collection of pus (dead and dying neutrophils plus proteinaceous exudate) that has built up within the tissue of the body. Mesenteric abscess is a rare, usually accounts for small percentage of intra-abdominal abscess after inguinal hernia surgery which is presented as left iliac fossa mass in postoperative period of open inguinal hernia surgery of left side and also presented with undescended testis of left side which is actual cause of formation of inguinal hernia of same side. Late onset mesh infection and post-operative peritonitis are very common in case of open hernia surgery. Intra-abdominal abscess cause significant morbidity and mortality. Surgery disturb the equilibrium between coagulation and fibrinolysis in the abdominal cavity in favour of coagulation system. Diminished fibrin degradation is a common pathway for the formation of abscess. We present a case of 40 years of male came with pain in left iliac fossa and lower abdomen for last 2 months with a swelling at LIF and hypogastric region for last 3 months with a previous history of hernia surgery of left side 2 month back which was diagnosed as mesenteric abscess and treated with exploratory laparotomy under general anaesthesia and abscess was drained.
\end{abstract}

Keywords: Mesenteric abscess, Inguinal hernia, Undescended testis, MRI, FNAC

\section{INTRODUCTION}

Intra-abdominal abscess continues to be an important and serious problem in surgical practice. These are collection of pus that are confined in peritoneal cavity by inflammatory barrier, usually contain a mixture of aerobic and anaerobic bacteria from gastrointestinal tract. The mesentery is a large, fan-shaped, double-layered fold of peritoneum that connects the jejunum and ileum to the posterior abdominal wall. Mesenteric abscess that developed after an inguinal hernia repair that utilized synthetic mesh; a rare condition developed after hernia surgery. Patient present with pain in left iliac fossa with pain in left iliac fossa and hypogastric region followed by hernia surgery of left side in afebrile condition without any comorbidities as a left iliac fossa mass.

\section{CASE REPORT}

A 40 years old male came with complain of pain in left iliac fossa for last 2 months with a swelling in left iliac fossa and hypogastric region for last 3 months with a history of open inguinal hernia surgery at left side near about 2 months ago with left sided undescended testis. Undescended test is actually the cause of formation of inguinal hernia of same side, because before birth, the testicles descends from the abdominal cavity to the scrotum, along an open channel that usually closes by the time a child is born. A hernia occurs when there a piece of intestine in this case most probably mesentery slides into the channel as in undescended testicles the connection between testicle and abdomen often fails to close. but patient treated by doing open inguinal hernia 
surgery without orchidopexy or orchidectomy. Patient was in afebrile condition, no history of any bleeding per stool, no history of vomiting, normotonic, non-diabetic. He presented with loss of appetite and loss of weight reduction.
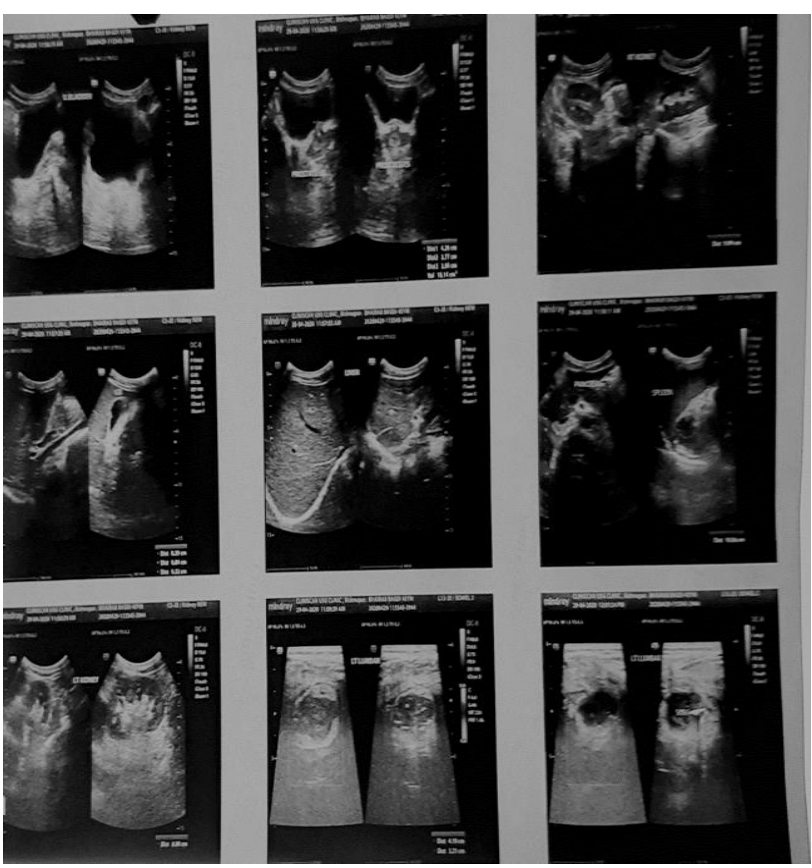

Figure 1: USG of whole abdomen $3.4 \mathrm{~cm} * 3.3 \mathrm{~cm}$ heterogeneously hypoechogenic mass noted in hypogastrium.

\section{On clinical examination}

GCS score is E4M5V5. Performance status 60, according to Karnofsky scale: pallor=absent, icterus=absent, edema=absent, cyanosis $=$ absent .

\section{Inspection}

There is an obious swelling in left iliac fossa and hypogastric region, no any skin discoloration.

\section{Palpation}

On palpation abdomen fill soft, a swelling $5 \mathrm{~cm} \times 4 \mathrm{~cm}$ mass palpated in left iliac fossa and hypogastric region. Mass is non reducible, not mobile. On Carnett's test swelling become less prominent that indicate it was an intra- abdominal swelling. In genitalia; lest testis was not palpated. Other systemic examinations are normal.

\section{Diagnostic investigations}

Complete blood count hemoglobin $\%=10, \mathrm{WBC}=6500$ per microliter, $\mathrm{RBC}=4.11$ million per microliter, $\mathrm{ESR}=26$ $\mathrm{mm} / \mathrm{h}$. Random blood sugar $80 \mathrm{mg} \%$, serum urea 27 $\mathrm{mg} \%$, serum creatinine $1 \mathrm{mg} \%$, serum sodium 131.7 mmol per litre, and serum potassium $3.91 \mathrm{mmol}$ per litre

\section{Liver function test}

Alkaline phosphatase=131 IU/l, serum glutamic pyruvic transaminase $=91$ IU/l, serum glutamic oxaloacetic transaminase $=33 \mathrm{IU} / \mathrm{l}$, total bilirubin $=0.65 \mathrm{mg} \%$, and albumin $=3.5 \mathrm{mg} \%$.

Serology

HIV1 and HIV1 non-reactive, HBS and anti HCV negative, prothrombin time $=12.4$, INR $=1.06$, beta $\mathrm{HCG}=0.47$, and serum $\mathrm{LDH}=454.3 \mathrm{U} / \mathrm{l}$.

\section{Radiological investigations}

Gall bladder was contracted.

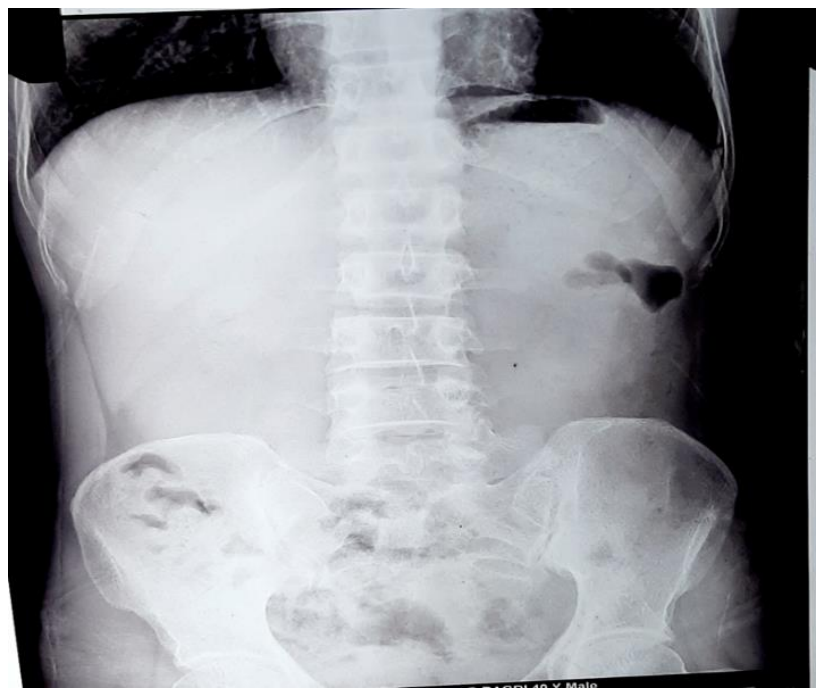

Figure 2: X-ray of whole abdomen (erect position) (within normal limit).

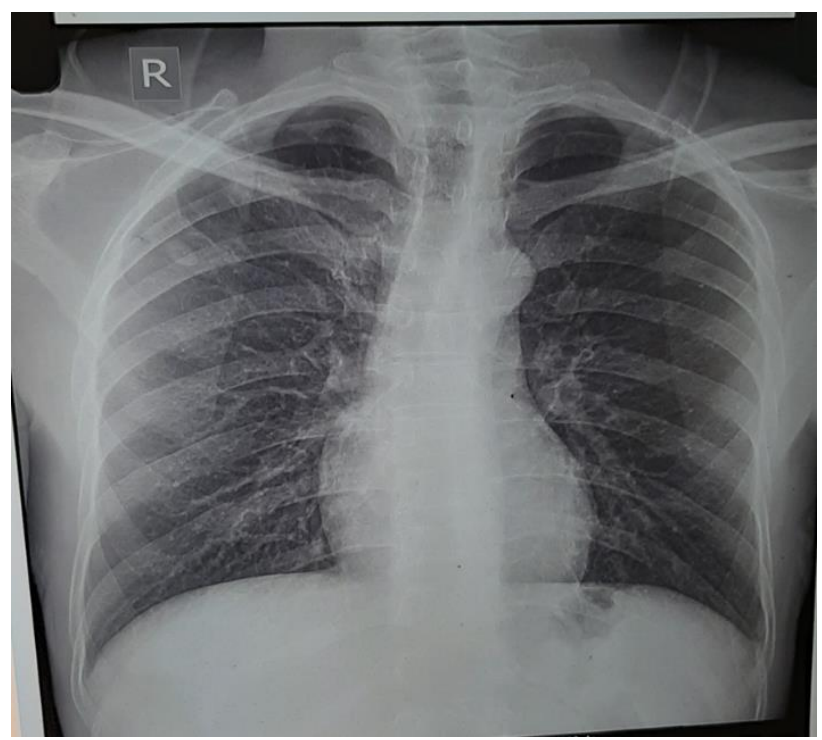

Figure 3: X-ray of chest (PA view) (within normal limit). 


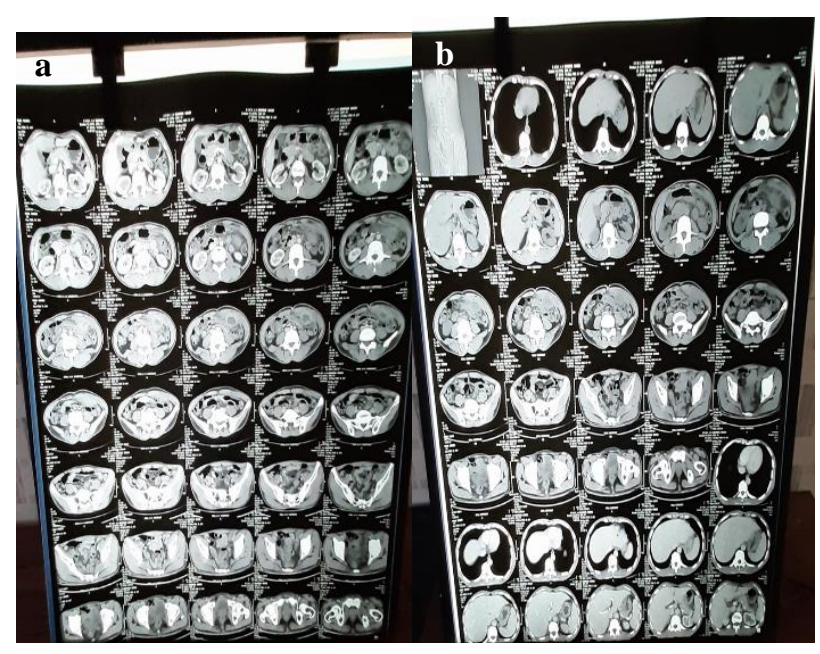

Figure 4 (a and b): MDCT scan of whole abdomen an irregular thick rim - enhancing necrotic SOL in the mesentery in left side - likely an abscess.

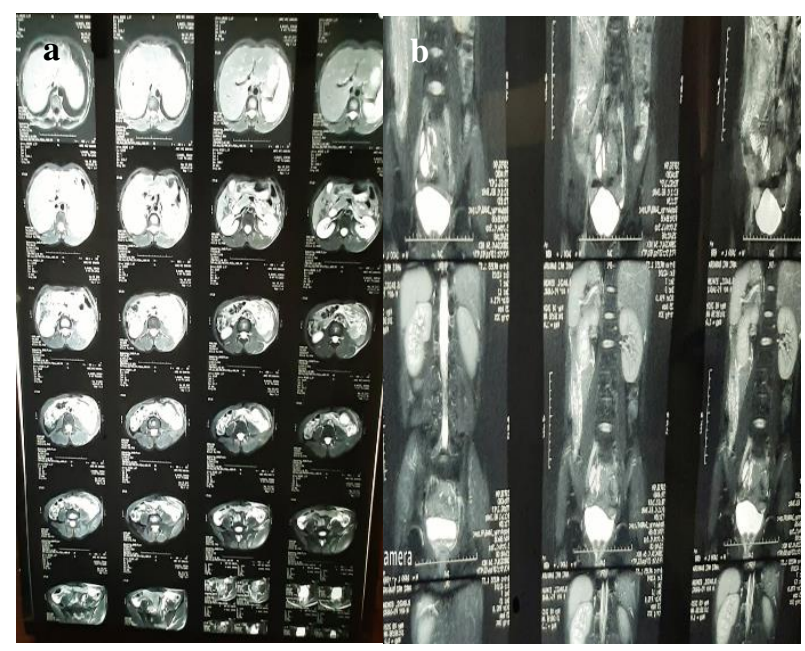

Figure 5: MRI of whole abdomen (a) mucosal oedema in descending and sigmoid colon and (b) gall bladder sludge.

\section{USG guided FNAC of LIF mass}

$\mathrm{M} / \mathrm{E}=$ smear shows cytomorphological features of mixed inflammatory cells predominantly neutrophils along with degenerated cells in a dirty background. No evidence of malignancy seen in the smear examined.

Overall features are suggestive of an abscess formation/suppurative lesion. Findings necrotic material removed over mesentery, left sighted testis is present close to deep inguinal ring - intra abdominal orchidectomy done. Now patient is asymptomatic.

\section{Management}

Patient was treated by exploratory laparotomy with intraabdominal orchidectomy under general aesthesia.

\section{DISCUSSION}

Mesenteric abscess is rare condition, may be find in chronic inflammatory bowel disease but it accounts small percentages of complications followed by inguinal hernia surgery. It is an important and serious complication in surgical practice. It mimics as left iliac fossa mass with pain in abdomen. So, it is least likely diagnosed as mesenteric abscess. Firstly, it diagnosed as intraabdominal mass as patient was also afebrile. Then it can be confirmed by MDCT and MRI of whole abdomen, and specially USG guided FNAC of mass that indicate presence of abscess. The presence of left sided undescended testis helps us to exclude the cause of inguinal hernia. After that exploratory laparotomy with intra-abdominal orchidectomy give complete cure.

\section{CONCLUSION}

A high index of clinical suspicion must be maintained towards the possibility of complication after the inguinal hernia surgery, in particular when same sided undescended testis was found. Detailed examination and by regular analysis of blood investigations, cross sectional abdominal images and FNAC of abscess help to identify the complication after inguinal hernia surgery that present as unexplained left iliac fossa mass.

Funding: No funding sources

Conflict of interest: None declared

Ethical approval: Not required

\section{REFERENCES}

1. Berg VDJC, Valois DJC, Go PM, Rosenbusch G. Detection of groin hernia with physical examination, ultrasound, and MRI compared with laparoscopic findings. Invest Radiol. 1999;34(12):739-43.

2. Ng TT, Hamlin JA, Kahn AM. Herniography: analysis of its role and limitations. Hernia. 2009;13(1):7-11.

3. Heise CP, Sproat IA, Starling JR. Peritoneography (herniography) for detecting occult inguinal hernia in patients with inguinodynia. Ann Surg. 2002;235(1):140-4.

4. Ekberg O. Complications after herniography in adults. Am J Roentgenol. 1983;140(3):491-5.

5. White JJ, Parks LC, Haller JA. The inguinal herniogram: a radiologic aid for accurate diagnosis of inguinal hernia in infants. Surgery. 1968;63(6):991-7.

6. Leander P, Ekberg O, Sjoberg S, Kesek P. MR imaging following herniography in patients with unclear groin pain. Eur Radiol. 2000;10(11):1691-6.

7. Hojer AM, Rygaard H, Jess P. CT in the diagnosis of abdominal wall hernias: a preliminary study. Eur Radiol. 1997;7(9):1416.

8. Quintas ML, Rodrigues CJ, Yoo JH, Rodrigues Junior AJ. Age related changes in the elastic fibre 
system of the interfoveolar ligament. Rev Hosp Clin Fac Med Sao Paulo. 2000;55:83-6.

9. Burcharth J, Pedersen M, Bisgaard T, Pedersen C, Rosenberg J. Nationwide prevalence of groin hernia repair. PLoS One. 2013;8:54367.

10. Abramson JH, Gofin J, Hopp C, Makler A, Epstein LM. The epidemiology of inguinal hernia. A survey in western Jerusalem. J Epidemiol Community Health. 1978;32:59-67.

11. Nilsson E, Kald A, Anderberg B, Bragmark M, Fordell R, Haapaniemi S, et al. Hernia surgery in a defined population: a prospective three years audit. Eur J Surg. 1997;163:823-9.

12. Ruhl CE, Everhart JE. Risk factors for inguinal hernia among adults in the US population. Am J Epidemiol. 2007;165:1154-61.

13. Zendejas B, Ramirez T, Jones T, Kuchena A, Ali $\mathrm{SM}$, Irizarry $\mathrm{HR}$, et al. Incidence of inguinal hernia repairs in Olmsted County, MN: a population-based study. Ann Surg. 2013;257:520-6.

14. Lau H, Fang C, Yuen WK, Patil NG. Risk factors for inguinal hernia in adult males: a case-control study. Surgery. 2007;141:262-6.

15. Liem MS, Graaf VDY, Zwart RC, Geurts I, Vroonhoven VTJ. Risk factors for inguinal hernia in women: a case-control study: The Coala Trial Group. Am J Epidemiol. 1997;146:721-6.

Cite this article as: Mahajan M. Mesenteric abscess presents as left iliac fossa mass in postoperative case of inguinal hernia surgery with undescended testis. Int Surg J 2020;7:2792-5. 